\title{
Surgery of Low-Grade Gliomas Near Speech-Eloquent Regions: Brainmapping versus Preoperative Functional Imaging
}

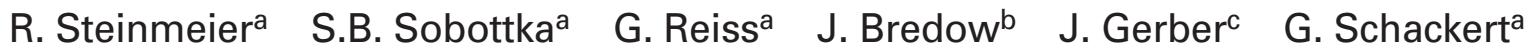 \\ ${ }^{a}$ Klinik für Neurochirurgie, \\ ${ }^{\mathrm{b}}$ Klinik für Nuklearmedizin, \\ ${ }^{\mathrm{c}}$ Abteilung für Neuroradiologie, Universitätsklinikum Carl Gustav Carus, Technische Universität Dresden
}

\section{Key Words}

Image-guided surgery · Brain mapping ·

Functional neuronavigation - Neurosurgery

\section{Summary}

The identification of eloquent areas is of utmost importance in the surgery of tumors located near speech-eloquent brain areas, since the classical concept of a constant localization was proven to be untrue and the spatial localization of these areas may show large interindividual differences. Some neurosurgical centers apply intraoperative electrophysiological methods that, however, necessitate the performance of surgery in the awake patient. This might be a severe burden both for the patient and the operating team in a procedure that lasts several hours; in addition, electrical stimulation may generate epileptic seizures. Alternatively, methods of functional brain imaging (e.g., PET, fMRI, MEG) may be applied, which allow individual localization of speech-eloquent areas. Matching of these image data with a conventional 3D-CT or MRI now allows the exact transfer of this information into the surgical field by neuronavigation. Whereas standards concerning electrophysiological stimulation techniques that could prevent a permanent postoperative worsening of language are available, until now it remains unclear whether the resection of regions shown to be active in functional brain imaging will cause a permanent postoperative deficit.

\author{
Schlüsselwörter \\ Bildgeführte Chirurgie · Brainmapping · Funktionelle \\ Neuronavigation · Neurochirurgie
}

\section{Zusammenfassung}

Die Identifikation sprachaktiver Areale ist von höchster Bedeutung bei der Operation von Tumoren in der Nähe des vermuteten Sprachzentrums, da das klassische Konzept einer konstanten Lokalisation des Sprachzentrums sich als unrichtig erwiesen hat und die räumliche Ausdehnung dieser Areale eine hohe interindividuelle Varianz aufweisen kann. Einige neurochirurgische Zentren benutzen deshalb intraoperativ elektrophysiologische Methoden, die jedoch eine Operation am wachen Patienten voraussetzen. Dies kann sowohl für den Patienten als auch das Operations-Team eine schwere Belastung bei diesem mehrstündigen Eingriff darstellen, zusätzlich können epileptische Anfälle durch die elektrische Stimulation generiert werden. Alternativ können Modalitäten des "functional brain imaging" (PET, fMRT, MEG usw.) eingesetzt werden, die die individuelle Lokalisation sprachaktiver Areale gestatten. Die Bildfusion dieser Daten mit einem konventionellen 3D-CT oder MRT erlaubt den exakten Transfer dieser Daten in den OP-Situs mittels Neuronavigation. Während Standards bei elektrophysiologischen Stimulationstechniken existieren, die eine permanente postoperative Verschlechterung der Sprachfunktion weitgehend verhindern, bleibt die Relevanz sprachaktiver Areale bei den neuesten bildgebenden Techniken bezüglich einer Operations-bedingten Verschlechterung der Sprachfunktion bisher noch unklar.

\begin{tabular}{ll}
\hline KARGER & @ 2002 S. Karger GmbH, Freiburg \\
$\begin{array}{l}\text { Fax +49761 4520714 } \\
\begin{array}{l}\text { E-mail Information@Karger.de } \\
\text { www.karger.com }\end{array}\end{array}$ & $\begin{array}{c}\text { Accessible online at: } \\
\text { www.karger.com/journals/onk }\end{array}$ \\
&
\end{tabular}


Due to the complex cerebral anatomy with closely located structures, where damages might cause severe neurological deficits, surgery of brain tumors is characterized by the difficulty to preserve structure and function while removing as much tumor tissue as possible. In some areas spatial orientation of the neurosurgeon may be relatively simple, while in others, especially where landmarks are missing or shifted by a space-occupying lesion, the orientation might be impaired. Thus, there is an increased requirement for intraoperative anatomical orientation for the localization of functionally active areas, and, in cases of specific tumors (e.g. low grade gliomas), for the objective assessment of the radicality of resection during surgery.

The significance of specific brain areas for complex functions remains unknown in many cases. It is hard to foretell if elimination of a specific area will cause functional deficiency. This is especially true for areas which might be involved in language production. The concepts of an interindividually constant localization of speech-eloquent areas developed in the last century by Broca [1] and Wernicke [2] had to be rejected [3], in contrast to the interindividual constant localization of the sensorimotor area that can often be identified unequivocally by preoperative MRI. Thus, if a tumor was located in or near speech-eloquent areas, in former times surgery was abandoned in order to avoid a reduction of quality of life by severe aphasia, or the tumor was only partially resected far away from assumed speech-eloquent areas.

Operative techniques with electrophysiological localization ('brainmapping' or 'electrical stimulation mapping') of speech eloquent areas were first inaugurated by Penfield et al. [4] in epilepsy surgery. A modified technique is used nowadays in some neurosurgical centers [5-14] in patients with low-grade gliomas or other lesions close to potentially speech-eloquent areas, in order to exactly localize the individual localization of these areas [15] and to prevent postoperative neurological or neuropsychological deficits by an intermittent monitoring of function (electrical stimulation of cortical functional areas and mapping). This method needs surgery in local anesthesia, a potentially severe psychological burden both for the patient and the operating team.

'Functional neuronavigation' may be considered as an alternative to the mapping in the awake patient. Image data of functional brain imaging (fBI), i.e. magnetoencephalography (MEG), functional magnetic resonance imaging (fMRI), and positron emission tomography (PET), are matched with conventional 3D-MRI or CT (computer tomography), and the complex matched data set containing information about localization of both the tumor and speech-eloquent areas is transferred into the surgical field by neuronavigation. However, it remains unclear whether the resection of presumed eloquent areas defined by $\mathrm{fBI}$ is necessarily accompanied by postoperative deficits.

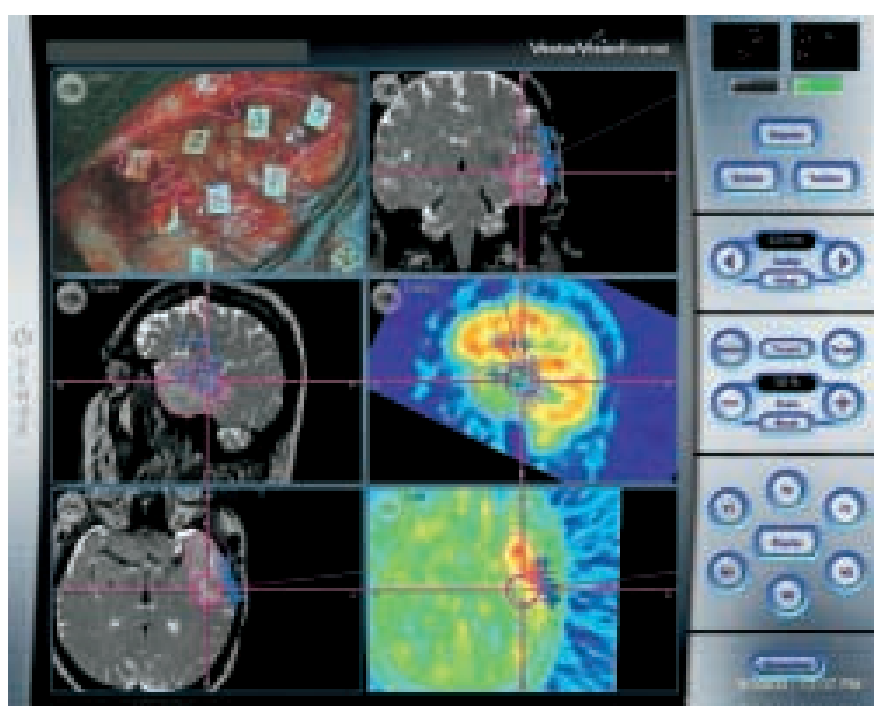

Fig. 1. Screenshot of the VectorVision ${ }^{2}$ navigational system (BrainLAB AG, Heimstetten, Germany) after matching T2-MRI (left side), speech activation PET (right middle) and OMF-DOPA-PET (right bottom). Stimulator positions during brain mapping are visualized by blue crosses and can be compared with speech-activated PET areas. The left upper window shows the video display from the brain surface (microscope view) with the various stimulation points being marked by numbers (tickets). In addition, the tumor contour (target area) below the brain cortex is visualized in the video display.

\section{Intraoperative Stimulation Mapping}

Whereas most of the intraoperatively applied electrophysiological methods ('phase reversal' for localization of the motor strip, AEP (acoustic evoked potentials) for monitoring of the vestibular nerve in case of acoustic neurinoma) can be performed under complete anaesthesia, intraoperative testing of higher cognitive functions, i.e. language, needs testing in the awake patient. Reversible loss of neuronal function is generated by the direct electrical stimulation of cortical areas involved in speech generation, manifesting as complete 'speech arrest' or 'speech disturbance' [16].

An adequate psychological preparation including neuropsychological testing of the patient is essential for a successful operation. Local anaesthetics (e.g. Bupivacain ${ }^{\circledR}$, Aventis Pharma, Bad Soden, Germany, or lidocain) are applied in sufficient doses in the area of the planned skin incision, and surgery is then performed with neuroleptic anaesthesia (fentanyl/propofol). After skin incision and trephination the dura is opened and the visible cortical surface marked by small 'tickets' in order to define the planned electrical stimulation matrix. The tickets and the results of stimulation mapping are used for a later definition of a safe resection border (fig. 1). A constant EEG is desirable for early detection of cortical ictal activity and in order to individually adjust the threshold for afterdischarge. The stimulation itself is performed by a bipolar 'stimulation forceps' with a distance of $5 \mathrm{~mm}$ between elec- 


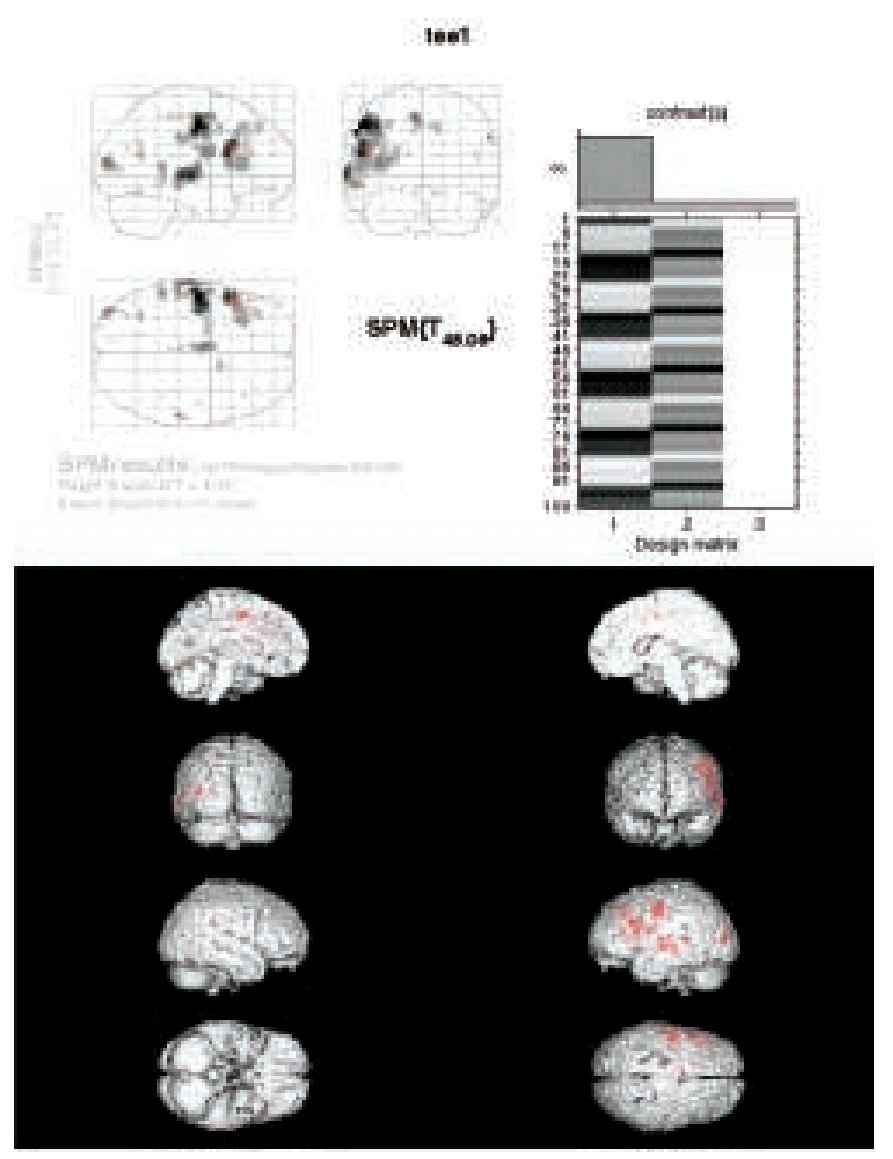

Fig. 2. Functional imaging of speech areas in a right-handed normal individual using fMRI. Visualization of speech activated areas (lower part) after evaluation using SPM (upper part). Verb generation was used as a paradigm in this example.

trodes and by applying biphasic square-wave constant current impulses (2-16 mA) with a frequency of $60 \mathrm{~Hz}$. The current should be triggered by EEG or should be individually adjusted to an event-related level. A stimulation matrix (grid) with a distance of $1 \mathrm{~cm}$ between the stimulated areas is accepted as standard. A remarkable limitation for applicable speech-paradigms is caused by the limited capacity of the patient being under sedation during surgery. Continuous naming of objects, presented visually every 4 or 5 seconds ('object naming') or generation of verbs according to the visual or acoustic presentation of nouns ('verb generation') have been proven to be useful. A tested area is marked as essential if a complete speech arrest is provoked reproducibly (twice in a sequence of three tests) and not caused by ictal activity. The consequence of a speech disturbance or hesitation is not unequivocal and further surgical procedure in these cases is not standardized. According to Ojemann et al. [3], such an area might be participating in language production, but is not considered essential. In the classical Broca-area inhibition of the motor cortex might be involved if the patient cannot articulate the leader phrase ('This is a ...'). A resection border of $1 \mathrm{~cm} \mathrm{[17]} \mathrm{up} \mathrm{to} 2$ $\mathrm{cm}$ [3] is regarded to be relatively safe in order to avoid postoperative deficits, although temporary deficits might also be seen under acceptance of these borders. The impact of the intensity of the current is unknown, since the spreading of the electrical stimulus in the individual case as well as the exact area of the inhibited neurons are not known. The additional time required for mapping varies between 15 and 45 min depending on the type and the number of the applied paradigms. In his classical work, Ojemann et al. [3] could not confirm the former concepts of an interindividually constant anatomical localization of speech-eloquent areas, as formerly pointed out by Broca [13] and Wernicke [2], although this group found a significant accumulation of eloquent areas in the Broca-area. One of the major findings of this group was that eloquent areas could be detected in a mosaic-like pattern at multiple localizations, often in areas smaller than $2 \mathrm{~cm}$ and preferentially, but not regularly, close to the dominant Sylvian fissure [3]. Other electrophysiological mapping-techniques, which allow the localization of the motor-strip ('phase-reversal' [18] or direct cortical stimulation), can, of course, additionally be used during the procedure.

In the current situation, brain mapping under local anesthesia is presumably the safest procedure for the detection of speech-eloquent areas. On the other hand, such testing in the awake patient means a strong psychological burden for the patient and is appropriate only for some selected patients. In addition, there is the risk of a stimulation-induced general epileptic seizure, for which reason some groups preoperatively apply antiepileptic drugs.

An alternative for surgery under local anesthesia is a twostaged surgery. During the first stage, subdural grids are implanted. Postoperatively, speech-eloquent areas can be localized by electrical stimulation [19]. In a second stage, the grids are removed and tumor-resection is performed under preservation of these areas.

\section{Functional Brain Imaging}

The individual localization of eloquent brain areas can be helpful for planning neurosurgical interventions. With the use of PET, fMRI, MEG, SPECT (single photon emission CT) and EEG mapping as different modalities for functional brain imaging, various parameters including blood perfusion, tissue metabolism and electromagnetic activity can be measured, visualized and assigned to certain brain areas.

Magnetoencephalography magnetic source imaging (MEG$M S I)$ registers and localizes cerebral magnetic events that are caused by electrical brain activity. The technique is based on large-array biomagnetometers (SQUIDS) for neuromagnetic source localization using dipole source localization algorithms [20]. The integration of a MEG dipole source into a 3D-MRI is known as magnetic source imaging (MSI). Changes of cortical magnetic potentials can be evoked by certain stimulation 
tasks. Peripheral stimulation of somatosensory tracts, intention of movements, and visual stimulation can evoke such changes in cortical activity at the somatosensory, motor, and visual cortex, respectively. Using this technique functional areas can be assigned to certain anatomical brain areas in the individual patient. In addition, the extension of functional brain areas can be determined by recently developed algorithms combined with suitable activation tasks (paradigms) allowing, for instance, the location of speech areas [21].

Functional magnetic resonance tomography (fMRI) is based on the difference of the paramagnetic activity of deoxyhemoglobin and the diamagnetic activity of oxyhemoglobin. Cortical activation is followed by a local increase of perfusion with a rising level of oxygenated blood in the postcapillary venous system. This results in changing 'dephasation' in the vicinity of the 'gradient field' visualized by gradient echo sequences (FLASH, EPI). The changes are mainly marked in the timeconstant $\mathrm{T} 2$ and $\mathrm{TR} *$ images that are characterized by the loss of phase coherence of the spin system. An intensification is possible by increasing the magnetic field and/or an extension of the echo time. An averaging of the signal is required for improvement of the signal-to-noise ratio (SNR, fig. 2). Standardized statistical procedures are not established yet. Various groups managed to exactly map certain functional brain areas, e.g. sensory and motor cortex, primary visual cortex and primary auditory cortex and multiple areas for intended speech in individual patients [43].

In positron emission tomography (PET), the application of fluor-labeled deoxyglucose or radioactively labeled water can be used to measure the regional glucose metabolism or cerebral perfusion, respectively.

Activation studies can discover functional eloquent brain areas. As a first step, imaging under silent conditions without activation is performed followed by activation studies using specific activation tasks. For localizing speech areas, object naming or verb generation are used. The tasks lead to an activation of the specific brain areas that are involved resulting in an increase of glucose metabolism or cerebral perfusion. A complex statistical evaluation as required by MEG or fMRI is usually not necessary according to the favorable SNR.

The transfer of fBI to the operative site has formerly been performed only by visual interpolation using anatomic landmarks (e.g. large veins) on 3D-MRI data sets [22, 23].

\section{Functional Neuronavigation}

An important development for intraoperative localization are neuronavigational systems. The principle of neuronavigation is based on mathematically connecting ('registering') the physical space (operative site) with the virtual image space of preoperative $3 \mathrm{D}-\mathrm{CT}$ or MRI. The connection is achieved by identifying corresponding points in the physical and virtual space building a transformation matrix. By interpolation, any point of the operative site can be assigned to a corresponding image point with usually an acceptable error. In contrast to frame-based stereotactic techniques, not every image slice of the $3 \mathrm{D}$-space is identified by the stereotactic localizer but by interpolation to the $3 \mathrm{D}$-space.

Usually a pointer is used for the technical realization of image-guided surgery. The pointer position is continuously and exactly recognized and visualized in the 3D-image data set on a computer workstation. Accordingly, the surgeon can compare the actual pointer position at the operative site with the corresponding position on the $3 \mathrm{D}$-images visualized on the computer screen.

Accuracy is a major concern in using neuronavigational systems. Various factors influence the total accuracy that results from adding the errors of the single factors [24]. The first factor depends on the images themselves. Voxel size and geometric distortion influence this factor. Geometric distortion is a common problem in MRI and is caused by inhomogeneity of the magnetic field, the gradient, and chemical shift. The second factor results from the quality of registration. Using skin markers (fiducials), the accuracy depends on the number of fiducials and their geometrical arrangement. A rather less important factor is the technical accuracy of the neuronavigational device that accounts for a deviation of usually less than $1 \mathrm{~mm}$ [25]. The total accuracy resulting from imaging, registration and technical deviation is known as application accuracy. In addition, intraoperative factors need to be taken into account. First, a deviation of the patient's head that is fixed in a headrest during surgery may lead to a 'positional shift'. Furthermore, a shifting of the brain in relation to the skull that is used for registration will cause an inaccuracy that has been termed 'brain shift' [26]. Brain shift results from differing physical-elastic properties of the brain, loss of cerebrospinal fluid during surgery, and shows topographical differences that can be related to a certain degree of brain fixation at the skull base and at the tentorium. Even the positioning of the head has an influence on the amount of brain shift, which makes the quantitative evaluation extremely difficult. Brain shift usually varies between operations and continuously increases during the surgical intervention.

The application accuracy reaches 2-3 mm under 'good' conditions and may amount to more than $7 \mathrm{~mm}$ following a 'bad' registration [27]. The individual influences of positional shift and brain shift are usually negligible at the start of surgery. However, as the surgical intervention progresses, it may occasionally rise to up to $1-2 \mathrm{~cm}$ making the neuronavigational guidance useless. The brain shift problem has not yet been solved.

The different functional brain imaging modalities (PET, MEG, fMRI) can be matched with conventional CT/MRI and in this way, the individually localized eloquent brain areas can be transferred to structural (anatomical) imaging data sets. The resulting complex functional and structural image data set can be transferred to the operative site using neuronavigation. 
This opens new perspectives for surgical interventions in or near eloquent brain regions [28] and may become an alternative to brain-mapping techniques in the future [29-32]. Accordingly, time-consuming intraoperative neurophysiological mapping techniques that usually put a great strain on the patients, may be abandoned one day. Figure 1 demonstrates the brain mapping techniques for speech localization in a patient operated under local anaesthesia. Using neuronavigation, findings of intraoperative electrical stimulation mapping are comparable to preoperative functional PET images.

\section{Discussion and Perspectives}

Since human speech is a complex phenomenon, the results from functional imaging and intraoperative brain mapping depend on the paradigms that are used for functional activation. Specific activation tasks involve only certain functional aspects and related brain regions. Defining suitable paradigms for pre- and intraoperative speech testing is still a great challenge for current neuropsychological research.

As intraoperative electrophysiological techniques for determining eloquent brain areas are still considered to be the gold standard by most neurosurgeons, exact comparison with pre- operative functional imaging is desirable. Due to technical limitations, a comparative analysis of both methods has only partially been realized so far [22, 28, 29, 33-42]. A prerequisite for any scientific evaluation of both methods remains the integration of the neurophysiological stimulation device in the neuronavigational system and the visualization of various stimulation points into the complex image data set. In addition, the data must be available for retrospective analysis [14]. If eloquent areas that have been determined by preoperative functional imaging (PET, MEG, fMRI) are found to correspond to results obtained by intraoperative cortical mapping, brain mapping may become dispensable. At that stage, patients may be operated under general anesthesia using preoperative functional data that are applied to the operative site using neuronavigational guidance. A key point for radical tumor resection in eloquent brain areas will be the question if essential and involved speech areas are distinguishable by preoperative functional imaging.

\section{Acknowledgement}

We thank Dr. K. Krishnan, Department of Neurosurgery, Dresden, Germany, for his critical review and help in manuscript preparation.

\section{References}

1 Broca P: Remarques sur le siège de la faculté du language articulé; suivies d'une observation d'aphémie (perte de la parole). Bull Soc Anat 1861;36:330-357.

2 Wernicke C: Der aphasische Symptomen-Komplex. Breslau, Cohn and Weigert, 1874.

3 Ojemann G, Ojemann J, Lettich E, Berger M: Cortical language localization in left, dominant hemisphere. An electrical stimulation mapping investigation in 117 patients. J Neurosurg 1989;71:316326.

4 Penfield W, Roberts L: Speech and Brain Mechanisms. Princeton, Princeton University Press, 1959.

5 Berger MS, Ojemann GA: Intraoperative brain mapping techniques in neuro-oncology. Stereotact Funct Neurosurg 1992;58:153-161.

6 Black PM, Ronner SF: Cortical mapping for defining the limits of tumor resection. Neurosurgery 1987;20:914-919.

7 Eisner W, Reulen HJ, Ilmberger J, Swozil U, Bise $\mathrm{K}$ : Intraoperative mapping of eloquent brain areas. Front Radiat Ther Oncol 1999;33:28-36.

8 Herholz K, Reulen HJ, von Stockhausen HM, Thiel A, Ilmberger J, Kessler J, Eisner W, Yousry TA, Heiss WD: Preoperative activation and intraoperative stimulation of language-related areas in patients with glioma. Neurosurgery 1997;41:12531260.

9 Lurito JT, Lowe MJ, Sartorius C, Mathews VP: Comparison of fMRI and intraoperative direct cortical stimulation in localization of receptive language areas. J Comput Assist Tomogr 2000;24:99105.

10 Ojemann GA: Mapping of neuropsychological language parameters at surgery. Int Anesthesiol Clin 1986;24:115-131.
11 Ojemann GA: Functional mapping of cortical language areas in adults. Intraoperative approaches. Adv Neurol 1993;63:155-163.

12 Ruge MI, Victor J, Hosain S, Correa DD, Relkin NR, Tabar V, Brennan C, Gutin PH, Hirsch J: Concordance between functional magnetic resonance imaging and intraoperative language mapping. Stereotact Funct Neurosurg 1999;72:95-102.

13 Yetkin FZ, Mueller WM, Morris GL, McAuliffe TL, Ulmer JL, Cox RW, Daniels DL, Haughton VM: Functional MR activation correlated with intraoperative cortical mapping. AJNR Am J Neuroradiol 1997;18:1311-1315.

14 Sobottka S, Bredow J, Beuthien-Baumann B, Reiss G, Schackert G, Steinmeier R: Comparison of functional brain PET images and intraoperative brainmapping data using image guided surgery. Image Guided Surgery (submitted).

15 Berger MS, Kincaid J, Ojemann GA, Lettich E: Brain mapping techniques to maximize resection, safety, and seizure control in children with brain tumors. Neurosurgery 1989;25:786-792.

16 Ojemann G, Mateer C: Human language cortex: Localization of memory, syntax, and sequential motor-phoneme identification systems. Science 1979;205:1401-1403.

17 Haglund MM, Berger MS, Shamseldin M, Lettich E, Ojemann GA: Cortical localization of temporal lobe language sites in patients with gliomas. Neurosurgery 1994;34:567-576.

18 Cedzich C, Taniguchi M, Schäfer S, Schramm J: Somatosensory evoked potential phase reversal and direct motor cortex stimulation during surgery in and around the central region. Neurosurgery 1996; 38:962-970.
19 Wyllie E, Luders H, Murphy D, Morris H, Dinner D, Lesser R, Godoy J, Kotagal P, Kanner A: Intracarotid amobarbital (Wada) test for language dominance: Correlation with results of cortical stimulation. Epilepsia 1990;31:156-161.

20 Cabrera Fernandez D, Grave de Peralta Menendez R, Gonzalez Andino SL: Some limitations of spatio-temporal source models. Brain Topogr 1995;7: 233-243.

21 Kober H, Moller M, Nimsky C, Vieth J, Fahlbusch $\mathrm{R}$, Ganslandt O: New approach to localize speech relevant brain areas and hemispheric dominance using spatially filtered magnetoencephalography. Hum Brain Mapp 2001;14:236-250.

22 Herholz K, Reulen HJ, von Stockhausen HM, Thiel A, Ilmberger J, Kessler J, Eisner W, Yousry TA, Heiss WD: Preoperative activation and intraoperative stimulation of language-related areas in patients with gliomas. Neurosurgery 1997;41:12531262.

23 Gallen CC, Bucholz R, Sobel DF: Intracranial neurosurgery guided by functional imaging. Surg Neurol 1994;42:523-530.

24 Maciunas RJ, Galloway RL Jr., Latimer JW, Cobb C, Zaccharias E, Moore A, Mandava VR: An independent application accuracy evaluation of stereotactic frame systems. Stereotact Funct Neurosurg 1992;58:103-107.

25 Kaus M, Steinmeier R, Sporer T, Ganslandt O, Fahlbusch R: Technical accuracy of a neuronavigation system measured with a high precision mechanical micromanipulator. Neurosurgery 1997;41: 1431-1437. 
26 Hill DL, Maurer CR, Maciunas RD, Barwise JA, Fitzpatrick JM, Wang MY: Measurement of intraoperative brain surface deformation under a craniotomy. Neurosurgery 1998;43:514-528.

27 Steinmeier R, Rachinger J, Kaus M, Ganslandt O, Huk W, Fahlbusch R: Factors influencing the application accuracy of neuronavigation systems. Stereotact Funct Neurosurg 2000;75:188-202.

28 Ganslandt O, Steinmeier R, Kober H, Vieth J, Kassubeck J, Romstöck J, Strauss C, Fahlbusch R: Magnetic source imaging combined with image-guided, frameless stereotaxy: A new method in surgery around the motor strip. Neurosurgery 1997;41:621628.

29 Watanabe E, Mayanagi Y, Kaneko Y: Identification of the central sulcus using magnetoencephalography and neuronavigator. No To Shinkei 1993;45: 1027-1032.

30 Rezai AR, Hund M, Kronberg E, Deletis V, Llinas R, Kelly PJ: Magnetoencephalography (MEG) Applications in image-guided stereotactic neurosurgery. Neurosurgery 1995;37:585.

31 Rezai AR, Hund M, Kronberg E, Deletis V, Zonenshayn M, Cappell J, Ribary U, Llinas R, Kelly PJ: Introduction of magnetoencephalography to stereotactic techniques. Stereotact Funct Neurosurg 1995;65:37-41.

32 Rezai AR, Hund M, Kronberg E, Zonenshayn M, Cappell J, Ribary U, Kall B, Llinas R, Kelly PJ: The interactive use of magnetoencephalography in stereotactic image-guided neurosurgery. Neurosurgery 1996;39:92-102.
33 Simos PG, Papanicolaou AC, Breier JI, Wheless JW, Constantinou JE, Gormley WB, Maggio WW: Localization of language-specific cortex by using magnetic source imaging and electrical stimulation mapping. J Neurosurg 1999;91:787-796.

34 Fandino J, Kollias SS, Wieser HG, Valavanis A, Yonekawa Y: Intraoperative validation of functional magnetic resonance imaging and cortical reorganization patterns in patients with brain tumors involving the primary motor cortex. J Neurosurg 1999;91:238-250.

35 Roberts TP, Zusman E, McDermott M, Barbaro N, Rowley HA: Correlation of functional magnetic source imaging with intraoperative cortical stimulation in neurosurgical patients. J Image Guid Surg 1995;1:339-347.

36 Roux FE, Boulanouar K, Ranjeva JP, Manelfe C, Tremoulet M, Sabatier J, Berry I: Cortical intraoperative stimulation in brain tumors as a tool to evaluate spatial data from motor functional MRI. Invest Radiol 1999;34:225-229.

37 Jack CR Jr., Thompson RM, Butts RK, Sharbrough FW, Kelly PJ, Hanson DP, Riederer SJ, Ehman RL, Hangiandreou NJ, Cascino GD: Sensory motor cortex: Correlation of presurgical mapping with functional MR imaging and invasive cortical mapping. Radiology 1994;190:85-92.

38 Vinas FC, Zamorano L, Mueller RA, Jiang Z, Chugani H, Fuerst D, Muzik O, Mangner TJ, Diaz FG: [15O]-water PET and intraoperative brain mapping: A comparison in the localization of eloquent cortex. Neurol Res 1997;19:601-608.
39 Bookheimer SY, Zeffiro TA, Blaxton T, Malow BA, Gaillard WD, Sato S, Kufta C, Fedio P, Theodore WH: A direct comparison of PET activation and electrocortical stimulation mapping for language localization. Neurology 1997;48:10561065

40 Ganslandt O, Fahlbusch R, Nimsky C, Kober H, Möller M, Steinmeier R, Romstöck J, Vieth J: Functional neuronavigation with magnetoencephalography: Outcome in 50 patients with lesions around the motor cortex. J Neurosurg 1999;91:73-

41 Krombach GA, Spetzger U, Rohde V, Gilsbach JM Intraoperative localization of functional regions in the sensorimotor cortex by neuronavigation and cortical mapping. Comput Aided Surg 1998;3:64

42 Nimsky C, Ganslandt O, Kober H, Moller M, Ulmer S, Tomandl B, Fahlbusch R: Integration of functional magnetic resonance imaging supported by magnetoencephalography in functional neuronavigation. Neurosurgery 1999;44:1249-1255.

43 Golder W: Functional magnetic resonance imaging - basics and applications in oncology. Onkologie 2002;25:28-31.

\section{BERLINER \\ KREBSGESELLSCHAFT E.V.}

AUSSCHREIBUNG

Forschungspreis der Berliner Krebsgesellschaft 2003

« Curt-Meyer-Gedächtnispreis »

Die Berliner Krebsgesellschaft e.V. stiftet einen Preis in Höhe von 10.000,00 EUR für herausragende wissenschaftliche Leistungen in derOnkologie.

Der Preis ist vorrangig für die Auszeichnung und Förderung von Wissenschaftlern gedacht, die das 40. Lebensjahr nicht überschritten haben und in Kliniken und Instituten im Land Berlin tätig sind.

Die Arbeit sollte bereits publizierte Ergebnisse enthalten. Die Publikation darf nicht mehr als ein Jahr zurückliegen. Ist das Manuskript zur Publikation eingereicht, muss das Begutachtungsverfahren abgeschlossen und die Arbeit zur Publikation angenommen sein.

Die Bewerbung ist an den Vorsitzenden der Berliner Krebsgesellschaft in dreifacher Ausfertigung unter Beifügung des Lebenslaufes und eines wissenschaftlichen Tätigkeitsberichtes zu senden.

Einsendeschluß ist der 15. Januar 2003 (Datum des Poststempels).

Berliner Krebsgesellschaft e.V.

Prof. Dr. Klaus Peter Hellriegel

Robert-Koch-Platz 7

10115 Berlin

Telefon: 030 / 2832400 - Telefax: 030 / 2824136

E-Mail: info@berliner-krebsgesellschaft.de

Internet: www.berliner-krebsgesellschaft.de 